\title{
Morphine: controlled trial of different methods of administration for postoperative pain relief
}

\author{
P C RUTTER, F MURPHY, H A F DUDLEY
}

\section{Summary and conclusions}

Forty-five patients who had undergone major operations were given a slow intravenous injection of morphine sulphate $(1 \mathrm{mg} / \mathrm{ml}$ saline) until their pain was relieved and were then randomly divided into three equal groups to receive different regimens of morphine sulphate over the next 72 hours. Patients in group A received 3.5 times the pain-relieving dose $(28-63 \mathrm{mg}$, mean $36 \mathrm{mg})$ by continuous intravenous infusion; those in group $B$ received the pain-relieving dose $(90-160 \mathrm{mg}$, mean $110 \mathrm{mg})$ intramuscularly, four-hourly for the first 24 hours, sixhourly for the next 24 hours, and then eight and 20 hours later; and those in group $C$ received the pain-relieving dose $(80-280 \mathrm{mg}$, mean $140 \mathrm{mg}$ ) intramuscularly as required. Pain was assessed on a linear analogue scale and vital capacity and peak expiratory flow rate measured 12-hourly. The mean pain score was significantly lower and respiratory function significantly better in group $A$ than in groups $B$ and $C$. Only one patient (in group $A$ ) required extra morphine.

Thus morphine administered by continuous intravenous infusion is superior to other regimens, giving better pain relief at a lower dosage.

\section{Introduction}

Many workers believe that continuous administration of intravenous opiates is superior to intermittent administration in controlling postoperative pain. ${ }^{1}{ }^{3}$ Though Church ${ }^{4}$ has reported a convincing retrospective questionary study using matched controls, the matter has never been formally tested, and intermittent injection (often as required) remains the commonest way of administering opiates for pain relief after operation. We describe a trial to test the hypothesis that continuous administration of intravenous morphine relieves pain more effectively than intermittent administration, and that smaller doses produce as good or better subjective and objective results.

\section{Patients and methods}

We studied 45 patients who had undergone major operations (cholecystectomy, highly selective vagotomy, or more extensive procedures). Once they had recovered consciousness and were complaining of pain they were given a slow intravenous injection of dilute morphine sulphate ( $1 \mathrm{mg} \mathrm{ml}$ saline) at a rate of about $2 \mathrm{mg}$ min until their pain was relieved. They were then randomly allocated, by drawing a card, to three separate groups to receive different morphine regimens over the ensuing 72 hours. Patients in group A received 3.5 times the pain-relieving dose by continuous intravenous infusion via a syringe pump; group $\mathrm{B}$ received the pain-relieving dose intramuscularly four-hourly for the first 24 hours, six-hourly for the next 24 hours, and then eight and 20 hours later; and group ( received the pain-relieving dose intramuscularly as required at the discretion of the nursing staff.

Partial blinding was achieved by giving a continuous infusion of saline via a syringe pump to patients in groups $\mathrm{B}$ and $\mathrm{C}$ and fourhourly injections of saline to patients in group A. Patients in groups A

Academic Surgical Unit, St Mary's Hospital, London W2 1NY P C RUTTER, $M B$, BS, senior house officer

F MURPHY, MB, FRCS, senior surgical registrar

H A F DUDLEY, CHM, FRCS, professor of surgery and director of unit and $B$ and the observer were not told by which route the morphine was being administered. "Escape clauses" allowed morphine to be given whenever the patient requested it and to be stopped when there was no pain. Pain was assessed on a linear analogue scale; graded from 0 (no pain) to 100 (the most severe imaginable). Each patient scored his pain at 12-hourly intervals, recording his overall pain in the past 12 hours. The analogue scale thus integrated each 12-hour period, so partially compensating for differences in dose schedules between the three groups.

Vital capacity (determined with a Vitalograph) and peak expiratory flow rate (determined with a Wright meter) were noted every 12 hours. Results were expressed as a percentage of the preoperative value. Level of consciousness at interview was assessed by one independent observer on a six-point scale. Results of respiratory function are expressed as means $\mathrm{SE}$ of mean. Since a normal distribution of data could not be assumed, statistical comparisons were made with the Mann-Whitney U test.

\section{Results}

Pain-Table I shows the pattern of subjective response to pain. The results in patients in group $\mathrm{A}$ (continuous intravenous infusion) were alwavs significantly different from those in patients in group $C$ (administration as required) $(\mathrm{P}<0.05)$. Results in patients in group $\mathrm{B}$ (regular intramuscular dose) were intermediate between the two but not significantly different from either.

TABLE I-Mean pain analogue score for thre' groups of 15 patients given parenteral morphine sulphate after operation. (For regimen in each group sec text)

\begin{tabular}{ccccc}
\hline $\begin{array}{l}\text { Time after } \\
\text { operation } \\
\text { (hours) }\end{array}$ & A & Group & \\
\cline { 2 - 4 } & $32 \cdot 5$ & 5 & C \\
\hline 12 & 26 & $50 \cdot 5$ & 60 \\
24 & 26 & 17 & 59 \\
36 & 19 & $39 \cdot 5$ & 57 \\
48 & 13 & $32 \cdot 5$ & 44 \\
60 & 16 & 24 & 41 \\
72 & & $12 \cdot 5$ & 41 \\
\hline
\end{tabular}

Respiratory function-A similar pattern to that for subjective pain response was observed for both vital capacity and expiratory flow rate tables II and III). The results in patients in group A were significantly superior to those in patients in group $\mathrm{C}(\mathrm{P}<0 \cdot 0) 5)$; the results in patients in group $\mathrm{B}$ were intermediate.

Level of consciousness-Continuous intravenous administration was associated with a slightly more blunted mental state than the other regimens. No patient, however, was judged to have received too much morphine, and the differences in levels of consciousness between the three groups were not significant.

Morphine dose-Patients in group B received 9()-160 mg (mean

TABLE II-Mean ( $\pm S E$ of mean) peak expiratory flow rate in three groups of 15 patients given parenteral morphine sulphate after operation, expressed as percintage of properative calue

\begin{tabular}{|c|c|c|c|}
\hline \multirow{2}{*}{$\begin{array}{c}\text { Time after } \\
\text { operation } \\
\text { hours) }\end{array}$} & \multicolumn{3}{|c|}{ Group } \\
\hline & $\mathrm{A}$ & B & C \\
\hline 12 & $29 \cdot 0: 3 \cdot 0^{*}$ & $27.8: 3.1$ & $24 \cdot 0: 2 \cdot 7$ \\
\hline 2.4 & $41 \cdot 1 \cdot 46^{*}$ & $39 \cdot 0 \cdot 3 \cdot 1$ & $34 \cdot 2: 3 \cdot 4$ \\
\hline 36 & $49 \cdot 2 \div 4 \cdot 7 *$ & $46 \cdot 0: 5 \cdot 0$ & $\begin{array}{r}39.5: 3.5 \\
40.0: 4.6\end{array}$ \\
\hline 48 & $56 \cdot 0 \cdot 5 \cdot 3^{*}$ & $49 \cdot 9: 5.7$ & $40 \cdot 0 \cdot 4 \cdot 6$ \\
\hline 60 & $65 \cdot 0 \cdot 5 \cdot 3 *$ & $61 \cdot 8: 6 \cdot 2^{*}$ & $44 \cdot 5: 4.7$ \\
\hline 72 & $59.5: 6 \cdot 0$ & $69 \cdot 5 \div 6 \cdot 6^{*}$ & $55 \cdot 8: 5 \cdot 2$ \\
\hline
\end{tabular}

*Significant difference from group C at 0.05 level (Mann-Whitney U test). 
TABLE III-Mean ( $\pm S E$ of mean) vital capacity in three groups of 15 patients given parenteral morphine sulphate after operation, expressed as percentage of preoperative value

\begin{tabular}{|c|c|c|c|}
\hline \multirow{2}{*}{$\begin{array}{l}\text { Time after } \\
\text { operation } \\
\text { (hours) }\end{array}$} & \multicolumn{3}{|c|}{ Group } \\
\hline & A & B & C \\
\hline $\begin{array}{l}12 \\
24 \\
36 \\
48 \\
60 \\
72\end{array}$ & $\begin{array}{c:c}29 \cdot 1 & 2 \cdot 8^{*} \\
42 \cdot 0 & 4 \cdot 1^{*} \\
43 \cdot 0 & 3 \cdot 9^{*} \\
50 \cdot 5 & 4 \cdot 2^{*} \\
55 \cdot 2 & 4 \cdot 2^{*} \\
60 \cdot 1 & 3 \cdot 8^{*}\end{array}$ & $\begin{array}{c:c}21 \cdot 0 & 1 \cdot 7 \\
33 \cdot 4 & 1 \cdot 6 \\
36 \cdot 1 & 1 \cdot 7 \\
41 \cdot 0 & 2 \cdot 7 \\
43 \cdot 1 & 2 \cdot 9 \\
52 \cdot 5 & 4 \cdot 1\end{array}$ & $\begin{array}{l:l}19 \cdot 7 & 1.6 \\
28.3 & 4 \cdot 1 \\
31 \cdot 2 & 2 \cdot 5 \\
37.2 & 3 \cdot 1 \\
41.0 & 2 \cdot 9 \\
50 \cdot 5 & 3.8\end{array}$ \\
\hline
\end{tabular}

*Significant difference from group C at $0.05 \mathrm{level}$ (Mann-Whitney U test).

$110 \mathrm{mg}$ ) of morphine during the 72 hours, while patients in group C received $80-280 \mathrm{mg}$ (mean $140 \mathrm{mg}$ ) indicating that difference in pain relief between the two groups was not due to the patients in group $\mathrm{C}$ experiencing difficulties or delay in obtaining morphine. By contrast, patients in group A received $28-63 \mathrm{mg}$ (mean $36 \mathrm{mg}$ ) of morphine over the 72 hours. Patients in group B did not require morphine in addition to their regular regimen, though this was freely available. Only one patient in group A required extra morphine (two doses of $10 \mathrm{mg}$ given intramuscularly). The titration doses in the trial had a modal value of $10 \mathrm{mg}$ (range $7 \cdot 5-18 \mathrm{mg}$ ), and 25 patients received this dose.

\section{Discussion}

This trial shows that intravenous infusion of morphine gives better pain relief at a lower dosage than other regimens. In particular, when morphine was given as required relatively large amounts were given with little effect. Though we do not think that the improved vital capacity and peak expiratory flow rate obtained with continuous infusion are anything more than objective measures of pain relief, it is interesting that pulmonary complications (as judged by clinical and radiological findings) occurred significantly more often in patients in groups B and C than in those in group A $(\mathbf{P}=0.032$, Fisher's exact test with Tocher's modification ${ }^{6}$ ); statistical analysis must, however, be applied cautiously to such data.

We do not suggest that continuous intravenous infusion of morphine is the optimum method of postoperative sedation, only that when morphine (or one of its analogues) is given, continuous intravenous infusion should be the method of choice. Though accidental overdosage from an inadequately controlled pump did not occur in this study, it is always possible, and it is best avoided by prescribing a standard dose in a standard volume administered by a pump with a single-speed motor. Variations in dosage are then only achieved by changing the motor drive.

\section{References}

${ }^{1}$ Fry EM. Postoperative pain. Br Med f 1976;2:817.

2 Leading article. Postoperative pain. Br Med f 1976;2:664.

${ }^{3}$ Stapleton JV, Austin KL, Mather LE. Postoperative pain. $\mathrm{Br} \mathrm{Med} f$ $1978 ; 2: 1499$.

Church JJ. Continuous narcotic infusions for relicf of postoperative pain. Br Med f 1979;1:977-9.

${ }^{5}$ Revill SI, Robinson JO, Rosen M, Hogg MI. The reliability of a linear analogue for evaluating pain. Anaesthesia $1976 ; 31: 1191-8$.

' Siegel S. Non-parametric statistics for the behavioural sciences. Tokyo: McGraw-Hill, 1956.

\title{
Standard exercise test to assess peripheral arterial disease
}

\author{
SUSAN P LAING， ROGER M GREENHALGH
}

\section{Summary and conclusions}

The fall in ankle systolic pressure after exercise serves as an objective indicator of the severity of haemodynamically important peripheral arterial disease. Twenty-six patients were studied to establish the effects of different work loads on the pressure response and to develop a test to standardise these effects. The patients walked for one or two minutes at $4 \mathrm{~km} / \mathrm{h}$ and one or two minutes at $6 \mathrm{~km} / \mathrm{h}$, and the fall in pressure was the same when measured immediately after exercise. The time taken for the pressure to return to the pre-exercise value varied.

As the fall in pressure occurs after only one minute of exercise at $4 \mathrm{~km} / \mathrm{h}$ on a $10 \%$ slope, this might be adopted as a standard test. It is acceptable to the patient, since claudication, angina, and shortness of breath rarely occur. It is sensitive enough to detect mild or asymptomatic disease and is useful in following up patients.

Charing Cross Hospital, London W6 8RF

SUSAN P LAING, BA, research assistant

ROGER M GREENHALGH, MCHIR, FRCs, senior lecturer in surgery and honorary consultant surgeon

\section{Introduction}

The pressure measured at the ankle with a pressure cuff and Doppler probe is an indirect measure of the arterial systolic pressure. The pressure may also be measured similarly at the calf and thigh. Although the absolute ankle pressure is important in some cases (for example, before selecting the site of an amputation), the pressure index is most widely used. This is the ratio of the ankle to the brachial pressure and in a normal healthy subject is approximately 1 . A pressure index below 0.9 indicates appreciable arterial disease.

The ankle systolic pressure and pressure index are reliable and accurate measurements. The pressure index has a day-to-day coefficient of variation of $6.4^{\circ}, 0$ in this laboratory. These measurements reflect the severity of the disease and can distinguish between single and multiple stenoses but cannot be used to predict the site of the disease. For example, an aortoiliac stenosis cannot be distinguished from a femoropopliteal stenosis by the pressure index alone. A further criticism of resting tests is that they do not measure the functional changes in blood flow that occur during exercise. Therefore, vascular laboratories commonly incorporate an exercise test when evaluating patients with intermittent claudication. ${ }^{12}$ The tests most commonly used are measurements of the claudication distance as the patient walks on a treadmill and of the ankle systolic pressure before and after a period of exercise.

The claudication distance (the point of onset of claudication, measured from the time the patient starts to walk) is an assessment of the disability of the patient but is subjective, may 